\title{
The story of neuromyelitis optica continues to be written
}

\author{
A história da neuromielite óptica ainda está sendo escrita \\ Yara Dadalti Fragoso
}

Departamento de Neurologia, Universidade Metropolitana de Santos, Sao Paulo SP, Brazil.

\section{Correspondence:}

Yara Dadalti Fragoso; Rua da Constituição, 374; 11015470 Santos

SP; Brazil. E-mail: yara@bsnet.com. br

Conflict of interest:

There is no conflict of interest to declare.

Received 13 April 2014 Accepted 28 April 2014

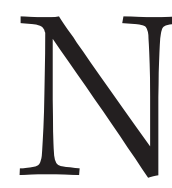
euromyelitis optica (NMO) is a relatively rare and particularly intriguing disease. NMO was first described by Devic ${ }^{1}$ and Gault ${ }^{2}$ at the end of the $19^{\text {th }}$ century, but it took around a century for this disease to be recognized as an clinical condition per $\mathrm{se}^{3}$. The diagnostic criteria were recently established and were revised in $2006^{4}$. The disease has probably existed for a long time ${ }^{5}$, but recognition of a specific demyelinating condition that only affects the spinal cord and the optical nerves was not easy. For some time it was considered to be a subtype of multiple sclerosis (MS $)^{6}$ known as "opticospinal MS". Although NMO is not a new disease, comprehension of it as an independent entity took its time.

The breakthrough for knowledge came with identification of a biomarker for NMO, the serum anti-aquaporin 4 (AQP4) antibody ${ }^{7}$. Unfortunately, this is not a specific marker since it can be present in other diseases and not all patients with NMO have detectable AQP4 antibodies in the serum ${ }^{8,9,10}$. Neurologists have little problem in diagnosing NMO in patients with severe myelitis and optical neuritis who also present AQP4 antibodies.

Patients with isolated or repetitive cases of myelitis or optical neuritis in association with AQP4 antibodies have been described. These patients do not fulfill the diagnostic criteria for NMO, but they have a spectrum of the disease, known as NMO spectrum disorder (NMOSD). This diagnosis is now better known among neurologists who see cases of myelitis or optical neuritis. If AQP4 antibodies are present in the patient's serum, it is not difficult to confirm a case of NMOSD.

However, when facing a case of NMOSD in which serum AQP4 antibodies cannot be detected, the differential diagnosis poses a great challenge. This issue of Arquivos de Neuropsiquiatria brings an important and interesting review by Sato et al on the subject of NMOSD with negative AQP4 antibodies ${ }^{11}$. They discuss the sensitivity of the laboratory methods used to detect the antibodies and elaborate on the added complication in diagnosing patients with NMOSD who are AQP4-negative and MOG-positive. Sato et al also present cases that mimic NMOSD in clinical presentation and imaging but were shown to be related to other diseases.

Over the last 15 years, we have learned that NMO is not a subtype of MS, and more recently, we have learned that NMO can be diagnosed in patients with a spectrum of the disease if they are positive for AQP4. Now we are learning that, even when patients are negative for AQP4, the diagnosis of NMOSD can be established. 
1. Devic E. Myélite aiguë dorso-lombaire avec névrite optique Autopsie. In Congrès Français de Médecine Paris: Asselin et Houzeau, Louis Savy 1895:434-439.

2. Gault F. De la neuromyélite optique aiguë. Thèse: Faculté de Médecine et de Pharmacie; 1894.

3. Wingerchuk DM, Hogancamp WF, O'Brien PC, Weinshenker BG. The clinical course of neuromyelitis optica (Devic's syndrome). Neurology 1999,53:1107-1114.

4. Wingerchuk DM, Lennon VA, Pittock SJ, Lucchinetti CF, Weinshenker BG. Revised diagnostic criteria for neuromyelitis optica. Neurology 2006;66:1485-1489.

5. Jarius S, Wildemann B. The history of neuromyelitis optica. J Neuroinflammation 2013;10:8.

6. Brain WR: Critical review: disseminated sclerosis. QJM 1930;23:343-391.

7. Yanagawa K, Kawachi I, Toyoshima Y, et al. Pathologic and immunologic profiles of a limited form of neuromyelitis optica with myelitis. Neurology. 2009;73:1628-1637.
8

Jarius S, Frederikson J, Waters P, et al. Frequency and prognostic impact of antibodies to aquaporin-4 in patients with optic neuritis. J Neurol Sci 2010;298:158-162.

9. Wandinger KP, Stangel M, Witte T, et al. Autoantibodies against aquaporin-4 in patients with neuropsychiatric systemic lupus erythematosus and primary Sjögren's syndrome. Arthritis Rheum 2010; 62:1198-1200.

10. Matsuoka T, Suzuki So, Suenaga T, Iwaki T, Kira J. Reappraisal of aquaporin-4 astrocytopathy in Asian neuromyelitis optica and multiple sclerosis patients. Brain Pathol 2011;21:516-532.

11. Sato DK, Callegaro D, Lana-Peixoto MA, Nakashima I, Fujihara K, BCTRIMS. Seronegative neuromyelitis optica spectrum - the challenges on disease definition and pathogenesis. Arq Neuropsiquiatr 2014;72:445-451. 